\title{
A simple thermogravimetric method for the evaluation of the degree of fly ash conversion into zeolite material
}

\author{
Izabela Majchrzak-Kucęba
}

Published online: 20 June 2012

(C) The Author(s) 2012. This article is published with open access at Springerlink.com

\begin{abstract}
The thermogravimetry was used for the evaluation of degree of conversion of fly ash into zeolite material alongside the CEC and XRD methods being currently proposed for this purpose. The present work proposes the calculation of the thermogravimetric fly ash-to-zeolite conversion factor, $\mathrm{CF}_{\mathrm{TGA}}$, based on the comparison of the mass loss of the commercial zeolite (standard) occurred during dehydration with that of the fly ash-derived zeolite. This mass loss is characteristic of a specific zeolite type, and the corresponding zeolite water content in the sample of zeolites indicates their degree of crystallinity and zeolite phase content. The use of the TGA method for the indirect determination of the fly ash-to-zeolite conversion factor would be preferable owing to its "speed" compared to other methods proposed for this purpose, as well as the capability to use a consistent procedure. Because of its short $\mathrm{CF}_{\mathrm{TGA}}$ determination procedure, the thermogravimetric method can be used for the control and determination of the quality of fly ash-derived zeolite in an industrial plant.
\end{abstract}

Keywords TGA · Fly ash-derived zeolite . Thermogravimetric conversion factor CF

\section{Introduction}

Fly ash is a material which, in spite of offering a fairly large spectrum of utilization possibilities that have been

I. Majchrzak-Kucęba ( $\square)$

Faculty of Engineering and Environmental Protection,

Czestochowa University of Technology, ul. Dąbrowskiego 73,

42-200 Czestochowa, Poland

e-mail: izak@is.pcz.czest.pl recognized so far (the building industry, underground mining), still leaves room for searching new methods of application, that would enable its values, and particularly chemical composition, to be more fully exploited. This fact is confirmed by numerous publications dedicated to new possibilities of fly ash utilization, which include the synthesis of zeolites [1-6].

The main indicator of the quality of fly ash-derived zeolite is the degree of fly ash conversion into the zeolite material, called also with the term "zeolite purity" or degree of crystallinity (in the case where X-ray analysis is used to determine the degree of fly ash conversion into the zeolite material). The relevant literature does not provide a precise method for determining quantitatively the zeolite phase content in a sample, and the term "purer zeolite material" denotes the one with the highest degree of fly ash conversion into the zeolite material. The fly ash-to-zeolite conversion degree is only determined indirectly utilizing methods that are commonly used for the evaluation of the physicochemical properties of zeolites, such as: XRD (for identify the crystalline zeolite and its type), CEC (for determining the cation exchange capacity), IR (for distinguishing zeolite structures), and BET (for determining the specific area and volume of pores). The indirect determination of the conversion degree, referred to in this study as the conversion factor $\mathrm{CF}$, consists in comparing the values obtained by these methods for fly ash-derived zeolites with the values obtained for commercial (pure) zeolites. Figure 1 summarizes the methods for the determination of the fly ash-to-zeolite conversion factor.

The majority of authors [7-13] determines the fly ashto-zeolite conversion degree in an indirect manner by testing the cation exchange capacity, CEC. The fly ash-tozeolite conversion factor is determined in this method by comparing the CEC value obtained for the fly ash zeolite 


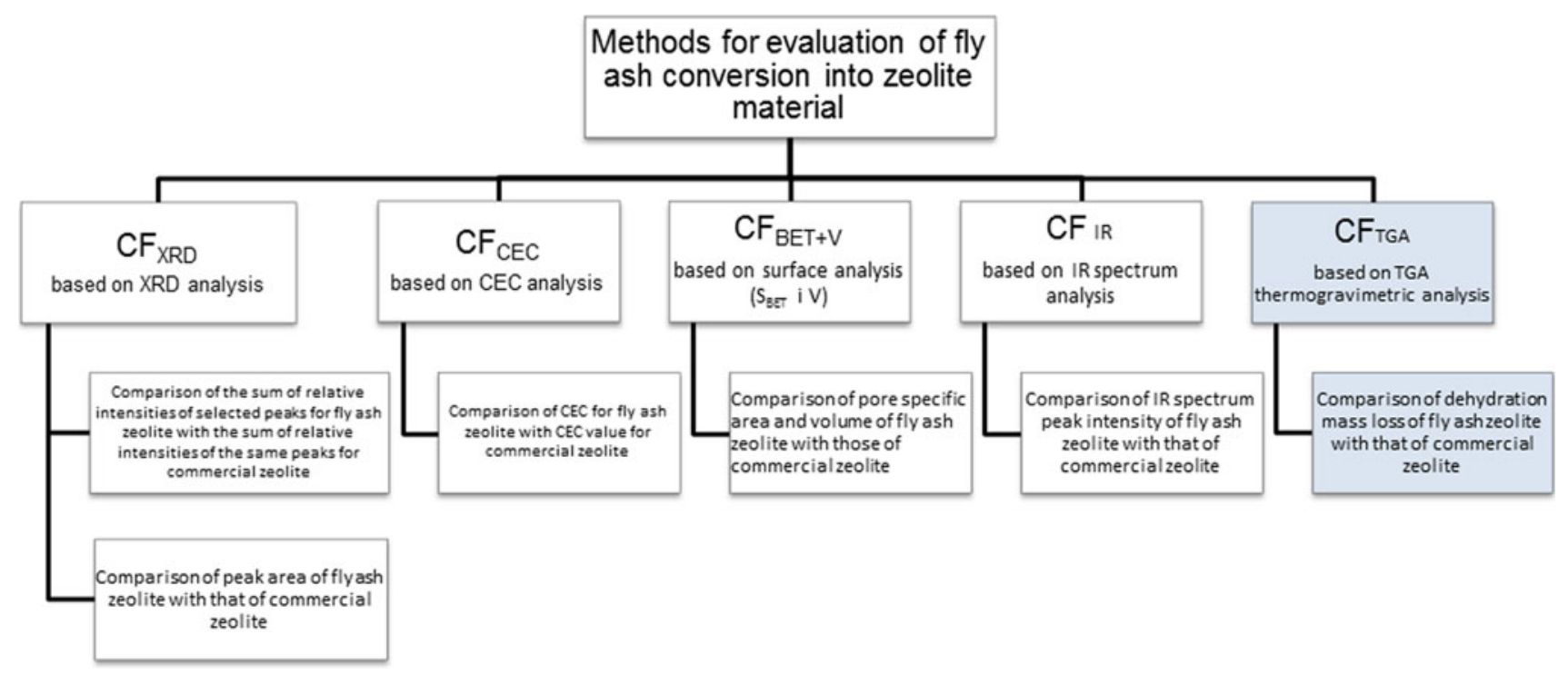

Fig. 1 Methods for the determination of the fly ash-to-zeolite conversion factor

material with the CEC value for the commercial zeolite of a purity of approx. $100 \%$. Unfortunately, CEC determination methodologies differ for different authors and are established for different ions, which is the source of numerous errors and makes the comparison of results difficult. Moreover, the CEC values depend on the temperature and, as shows by studies [14], also on the synthesis method and process parameters. Most often, the CEC is determined for the ions $\mathrm{NH}_{4}{ }^{+}, \mathrm{Cd}^{2+}, \mathrm{Pb}^{2+}, \mathrm{Zn}^{2+}$ and $\mathrm{Ba}^{2+}$ [6]. Another method being commonly used for the indirect determination of the fly ash-to-zeolite conversion degree is the quantitative XRD analysis. In the XRD method, the fly ash-to-zeolite conversion degree is evaluated via the analysis of the intensity of the main peak, the analysis of so called relative peak intensity and comparing the area of the peak for the fly ash zeolite with the area of the same peak for the commercial zeolite. According to the calculation methodology proposed by Rayalu et al. [15], the fly ash-tozeolite conversion degree, as defined in the work as the $\mathrm{X}$-ray conversion factor $\left(\mathrm{CF}_{\mathrm{XRD}}\right)$, is expressed as the ratio of the sum of the relative intensities of 10 individual peaks characteristic of a given fly ash zeolite type (e.g. Na-A) to the sum of the relative intensities of 10 individual peaks characteristic of a standard (that is the commercial zeolite, e.g. Na-A). Rayalu et al. [15] have also proposed the use of IR spectroscopy for the determination of the fly ash-tozeolite conversion degree by comparing the intensities of peaks at $560 \mathrm{~cm}^{-1}$ (asymmetric vibrations bending the $\mathrm{Si}(\mathrm{Al})-\mathrm{O}$ bonding) and at $464 \mathrm{~cm}^{-1}$ (internal vibrations in tetrahedrons) of fly ash zeolite and commercial zeolite. This coefficient is defined in this work as the spectroscopic conversion factor $\left(\mathrm{CF}_{\mathrm{IR}}\right)$. More recently, Gross et al. [16, 17] have proposed the determination of the conversion factor, which is referred to in this work as the surface conversion factor $\left(\mathrm{CF}_{\mathrm{BET}+\mathrm{V}}\right)$, by comparing the magnitudes of the surface area and volume of micropores of the fly ash zeolite with those of the commercial zeolite. The reported literature data show that there is no consistent methodology for the indirect determination of the fly ashto-zeolite conversion factor, which make the comparison of results reported by different authors difficult. In addition, the presence of more than one zeolite phase hinders the use of the conversion factor determination methods described. Bearing in mind that each method is based on some simplifications, it would be necessary to rely on the results from several methods in order to obtain the complete information. It would be justifiable, therefore, to jointly use several methods to determine the $\mathrm{CF}$ and to check the possibility of using other research methods to this end. The thermogravimetric analysis (TGA), which is widely used for the evaluation of the degree of dehydration of zeolite materials and their thermal stability, has not been proposed to date for the indirect determination of the conversion factor. For the first time, such an attempt was made in the present work by developing the thermogravimetric conversion factor $\left(\mathrm{CF}_{\mathrm{TGA}}\right)$.

The aim of this work was estimated the possibility of use of the thermogravimetric analysis (TGA), for the evaluation of the fly ash-to-zeolite conversion factor, $\mathrm{CF}_{\mathrm{TGA}}$.

\section{Experimental}

\subsection{Synthesis}

Zeolite synthesis reactions were carried out in a $5 \mathrm{~L}$ reaction vessel Hell, as presented in Fig. 2.The synthesis processes were run aimed at obtaining two zeolite phases, 


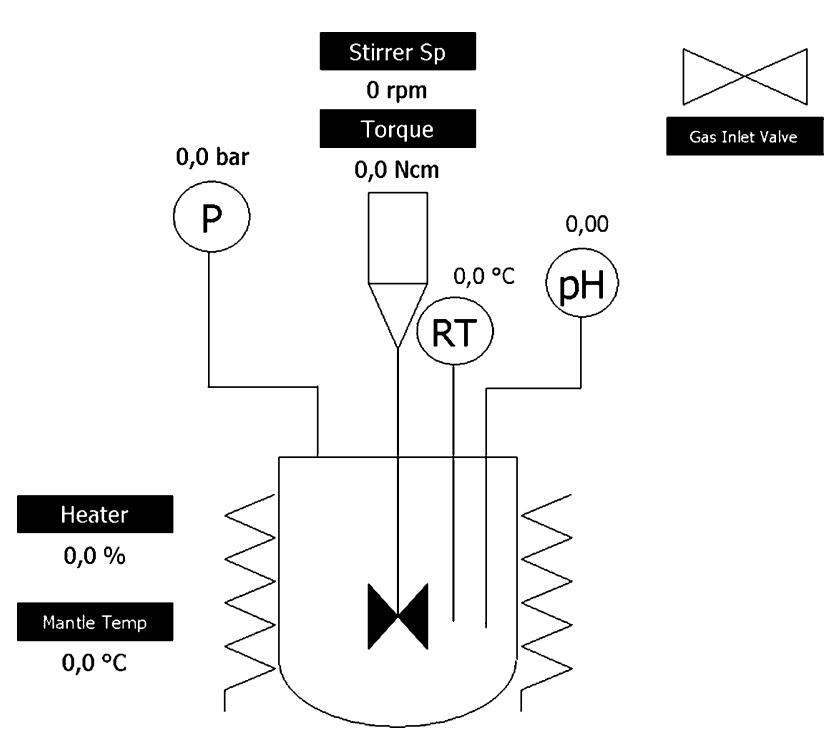

Fig. 2 Schematic diagram of the pressure reactor used for the syntheses of zeolite materials from fly ash

Na-A and Na-P1, differing in the content of the zeolite phase. Coal fly ash obtained from a utility power station in Poland (PC) was used for the synthesis. The fly ash was chemically analyzed and used to prepare the zeolite materials. The chemical composition of starting fly ash is given in Table 1. The main components of coal fly ash were $\mathrm{SiO}_{2}$ and $\mathrm{Al}_{2} \mathrm{O}_{3}$. The $\mathrm{SiO}_{2} / \mathrm{Al}_{2} \mathrm{O}_{3}$ ratio for fly ash used for zeolite synthesis was 2.43 . The value of this ratio for zeolite synthesis is very important, as the formation of the particular zeolite species dependents on the $\mathrm{Si} / \mathrm{Al}$ ratio in the starting material.

\subsubsection{Na-P1 zeolite}

For producing the Na-P1 zeolite material, the classic method was used, whereby fly ash ( $20 \mathrm{~g})$ was mixed with a $2.0 \mathrm{~mol} / \mathrm{dm}^{3}$ sodium hydroxide solution $\left(160 \mathrm{~cm}^{3}\right)$ and heated at $125{ }^{\circ} \mathrm{C}$ for 8,12 and $24 \mathrm{~h}$, respectively. Due to the fact that the Na-P1 zeolite samples obtained by this method had still a lot of impurities left from the fly ash, also high degree of purity Na-P1 zeolite was synthesized (following the 2-stage hydrothermal method based on the $\mathrm{Si}$ and Al fly ash extract, as proposed by [18]). To obtain the extract, a $2 \mathrm{~mol} / \mathrm{dm}^{3} \mathrm{NaOH}$ solution was used, which was mixed with fly ash in a ratio of $2.5: 1$, heated for $6 \mathrm{~h}$ at a temperature of $90{ }^{\circ} \mathrm{C}$ and, finally, filtered. Thus obtained filtrate was heated at a temperature of $90{ }^{\circ} \mathrm{C}$ for $48 \mathrm{~h}$ to obtain a high degree of purity Na-P1 phase.

\subsubsection{Na-A zeolite}

For producing the Na-A zeolite, a synthesis based on the fly ash extract with an addition of sodium aluminate, $\mathrm{Al}_{2} \mathrm{O}_{3}$, was used, to obtain the $\mathrm{Si} / \mathrm{Al}$ ratio in the initial gel appropriate for obtaining the Na-A zeolite phase. This ratio should be from 2 to 2.4. This method was employed with the aim of obtaining high degree of purity Na-A zeolite based on fly ash. In the first step (referred to as activation) an $\mathrm{Si}$ and $\mathrm{Al}$ filtrate was obtained from the fly ash by treating with an $\mathrm{NaOH}$ solution at $80-88^{\circ} \mathrm{C}$ for $2 \mathrm{~h}$. To optimize the process, $\mathrm{NaOH}$ solutions of varying concentrations, i.e. $1.5 ; 3.3 ; 5$ and $6.5 \mathrm{~mol} / \mathrm{dm}^{3}$, were used. Using solutions varying in concentration made it possible to obtain filtrates of varying $\mathrm{Si} / \mathrm{Al}$ ratio, because the dissolution degree of $\mathrm{Si}$ and $\mathrm{Al}$ depends on the solution concentration, increasing with its increase. Then, to each of the initial filtrates an additional aluminium source was added in the form of $\mathrm{NaAlO}_{2}$ dissolved in the $\mathrm{NaOH}$ solution of the identical concentration as the one used for obtaining the initial filtrate. The addition of the same mount of $\mathrm{NaAlO}_{2}$ to each of the obtained filtrates allowed initial gels for synthesis to be obtained in varying $\mathrm{Si} / \mathrm{Al}$ ratio $(2.0 ; 2.15$; $2.4 ; 2.55$, respectively, for using concentrations of $1.5 ; 3.3$; 5 and $6.5 \mathrm{~mol} / \mathrm{dm}^{3}$ ). The addition of aluminium was necessary because of the low content of aluminium in the filtrates obtained from the fly ash. The second step, that is crystallization, was conducted using different synthesis durations (i.e. 3, 4, 5, and $6 \mathrm{~h}$ ).

All the obtained samples were filtered, washed with distilled water in order to remove the remaining $\mathrm{NaOH}$, and dried at $120{ }^{\circ} \mathrm{C}$ for $12 \mathrm{~h}$. For comparison, the commercial (pure) Na-A and Na-P1 zeolite were also used for the tests.

\subsection{Characterization}

The formation of a zeolites was confirmed by powder X-ray diffraction. XRD patterns were recorded on a Bruker AXS D8 Advance diffractometer using $\mathrm{CuK} \alpha$ radiation of wavelength $0.15405 \mathrm{~nm}$. Diffraction data were recorded

Table 1 Chemical composition of fly ash (wt \%)

\begin{tabular}{|c|c|c|c|c|c|c|c|c|c|c|c|c|}
\hline \multirow[t]{2}{*}{ Fly ash } & \multicolumn{12}{|c|}{ Element as oxide } \\
\hline & LOI* $^{*}$ & $\mathrm{SiO}_{2}$ & $\mathrm{Al}_{2} \mathrm{O}_{3}$ & $\mathrm{Fe}_{2} \mathrm{O}_{3}$ & $\mathrm{CaO}$ & $\mathrm{MgO}$ & $\mathrm{Na}_{2} \mathrm{O}$ & $\mathrm{K}_{2} \mathrm{O}$ & $\mathrm{Mn}_{2} \mathrm{O}_{3}$ & $\mathrm{P}_{2} \mathrm{O}_{5}$ & $\mathrm{TiO}_{2}$ & $\mathrm{SiO}_{2} / \mathrm{Al}_{2} \mathrm{O}_{3}$ \\
\hline 1 & 1.26 & 54.77 & 22.56 & 4.46 & 7.9 & 0.66 & 1.78 & 1.09 & 0.16 & 0.004 & 2 & 2.43 \\
\hline
\end{tabular}

* LOI loss on ignition 
between $6-60^{\circ} 2 \Theta$ at an interval of $0.5^{\circ} 2 \Theta$. The X-ray method was also used for the calculation of the XRD factor of fly ash conversion to zeolite material $\left(\mathrm{CF}_{\mathrm{XRD}}\right)$ by comparing the relative intensities of peaks characteristic of the Na-A and Na-P1 fly ash zeolites with the relative intensity of the same peaks for the commercial zeolites, following the procedure described in [15].

The cation exchange capacity (CEC) of zeolite materials was assessed based on the $\mathrm{NH}_{4}{ }^{+}$ammonium ion exchange according to the US EPA SW-846 method described by Fan et al. [19]. The assay involves mixing of $4 \mathrm{~g}$ of zeolite sample with $33 \mathrm{~cm}^{3}$ of sodium acetate solution $(1 \mathrm{~mol} /$ $\mathrm{dm}^{3}$ ) and shaking for $5 \mathrm{~min}$, followed by decanting. The solid residue was shaken again with a fresh sodium acetate solution. The process was repeated 3 times, after which the solid residue was washed with $33 \mathrm{~cm}^{3}$ of ethanol. Next, ammonium acetate solution $\left(1 \mathrm{~mol} / \mathrm{dm}^{3}\right)$ was added to exchange the absorbed sodium ions for ammonium ions. The obtained filtrate was diluted to $100 \mathrm{~cm}^{3}$ with ammonium acetate solution $\left(1 \mathrm{~mol} / \mathrm{dm}^{3}\right)$ and the sodium concentration was determined by ion chromatography (using an 883 Basic IC plus chromatograph by Metrohm). The obtained $\mathrm{CEC}$ values were used for calculation of $\mathrm{CF}_{\mathrm{CEC}}$ by comparing the CEC value obtained for the fly ashderived zeolite with the CEC value for the commercial zeolite (standard). The effect of temperature on the zeolite samples was studied by a Mettler TGA/SDTA 851e thermobalance. The zeolite samples were heated up from room temperature to $500{ }^{\circ} \mathrm{C}$ at a rate of $20{ }^{\circ} \mathrm{C} \mathrm{min}-1$ in a flow $\left(50 \mathrm{~cm}^{3} \mathrm{~min}^{-1}\right)$ of nitrogen. The mass loss in the TG curve $\left(25-500{ }^{\circ} \mathrm{C}\right)$ was chosen for the conversion factor calculations, as it is this stage that is connected with desorption of surface-adsorbed water, removal of water molecules from the channels/void system of the zeolite structure and dehydration of hydrated cations positioned in the zeolite framework.

All measurements were blank-curve corrected. For temperature calibration, standard substances of known phase change temperatures were used.

\section{Results and discussion}

\subsection{Characterization of fly ash-derived zeolite}

The diffraction patterns for the Na-P1 products obtained by two methods are shown in Fig. 3.

In the case of using $2 \mathrm{~mol} / \mathrm{dm}^{3} \mathrm{NaOH}$ solution (Fig. 3a), with the increase in synthesis duration, the intensity of the $\mathrm{I}_{\mathrm{Na}-\mathrm{P} 1(301)}$ peak increases, which is indicative of an increased Na-P1 zeolite content of the sample. At the same time, the intensity of the quartz characteristic peak, $\mathrm{I}_{\mathrm{Q}}$, increases, which confirms the solution of the quartz and its
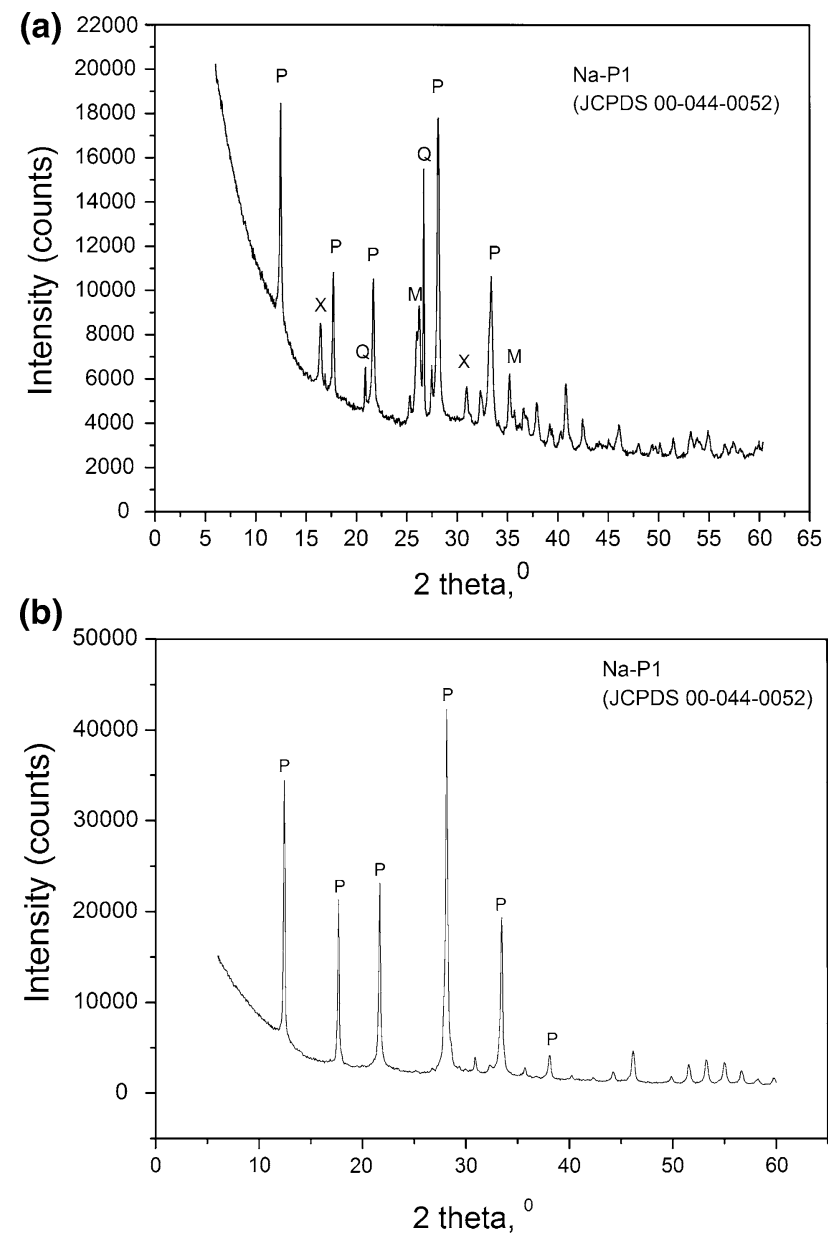

Fig. 3 XRD of the Na-P1 zeolite phases obtained by fly ash modification $\mathbf{a}$ as obtained by the hydrothermal method; $\mathbf{b}$ as obtained by the 2 -stage method: $Q$ quartz, $M$ mullite, $P$ Na-P1 zeolite, $X$ F-FAU zeolite

inclusion in the reaction, which increase with the synthesis time. In Fig. 3a we can notice the unchanging intensity of the mullite characteristic peak, $\mathrm{I}_{\mathrm{M}}$, which confirms the fact that regardless the synthesis duration the mullite does not dissolve in the alkaline medium and does not enter into reaction. As a result of the performed two-stage hydrothermal synthesis based on the fly ash $\mathrm{Si}$ and $\mathrm{Al}$ extract (Fig. 3b), a Na-P1 zeolite with a high degree of purity was obtained, which could be inferred from the XRD (no peaks characteristic of fly ash).

Figure 4 shows XRD diffraction patterns for the Na-A zeolite products obtained as a result of the syntheses carried out. As can be noticed from Fig. 4, in all of the synthesis conditions used, the Na-A zeolite phase was obtained in the samples, except for the sample activated with the $6.5 \mathrm{~mol} / \mathrm{dm}^{3} \mathrm{NaOH}$ solution and then subjected to $6 \mathrm{~h}$ ' crystallization. The presence of (hydroxyl) sodalite was found in that sample. This zeolite accompanied the Na-A phase in the case of making activation with the $6.5 \mathrm{~mol} / \mathrm{dm}^{3}$ 
Fig. 4 XRD of the zeolite materials obtained by the method based on the fly ash extract with the addition of sodium aluminate, $\mathrm{NaAlO}_{2}$, while making fly ash activation with $\mathrm{NaOH}$ solution in a concentration of $1.5 ; 3.3$ (a) and $5 ; 6.5 \mathrm{~mol} / \mathrm{dm}^{3}$ (b) $\left(\right.$ at $80{ }^{\circ} \mathrm{C}$ for $2 \mathrm{~h}$ ) and conducting crystallization at $100-105{ }^{\circ} \mathrm{C}$ for $3,4,5$ and $6 \mathrm{~h}$, respectively

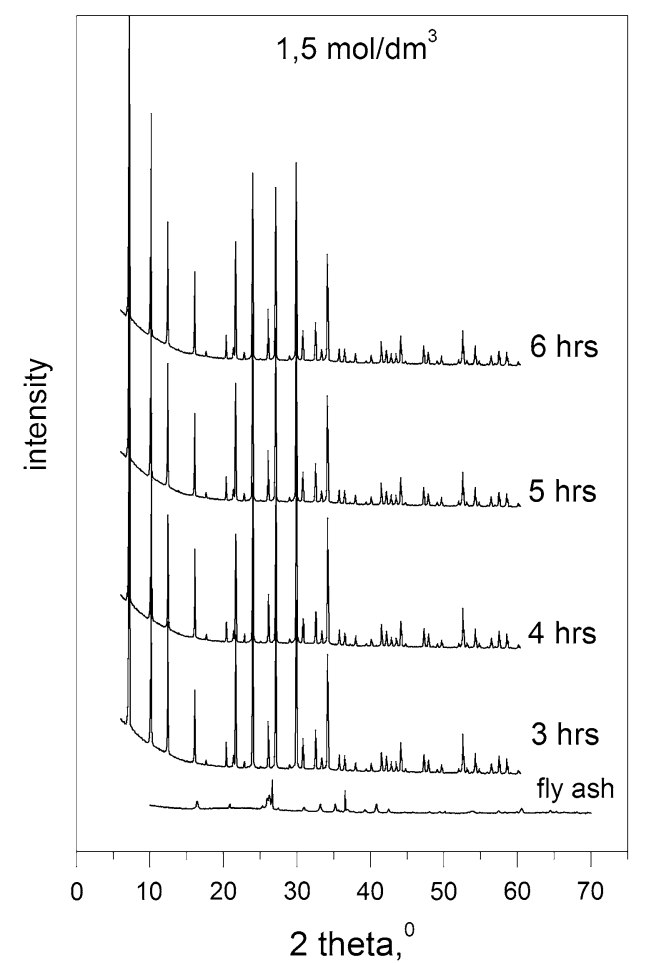

(a)

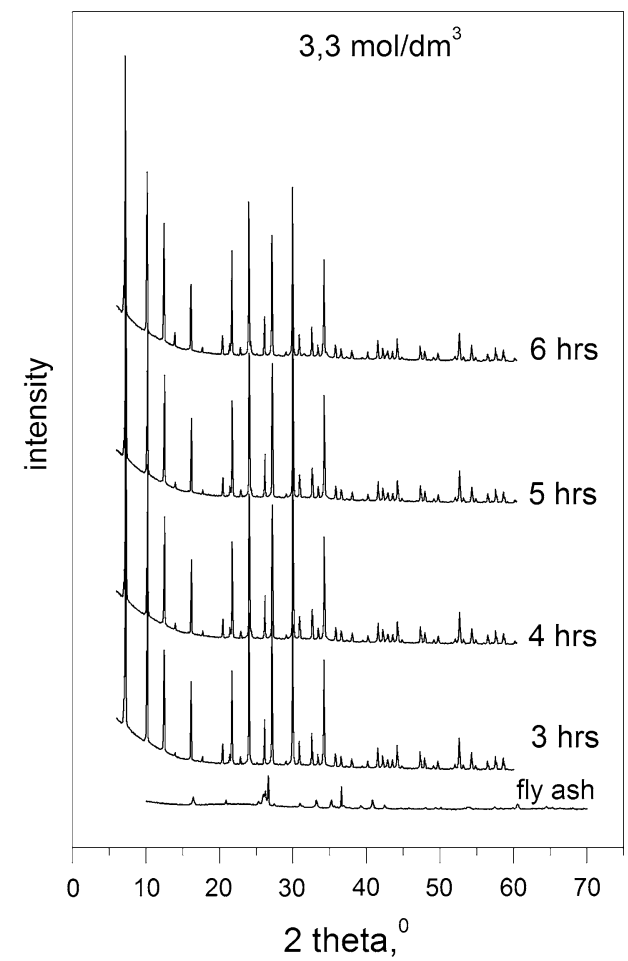

(b)

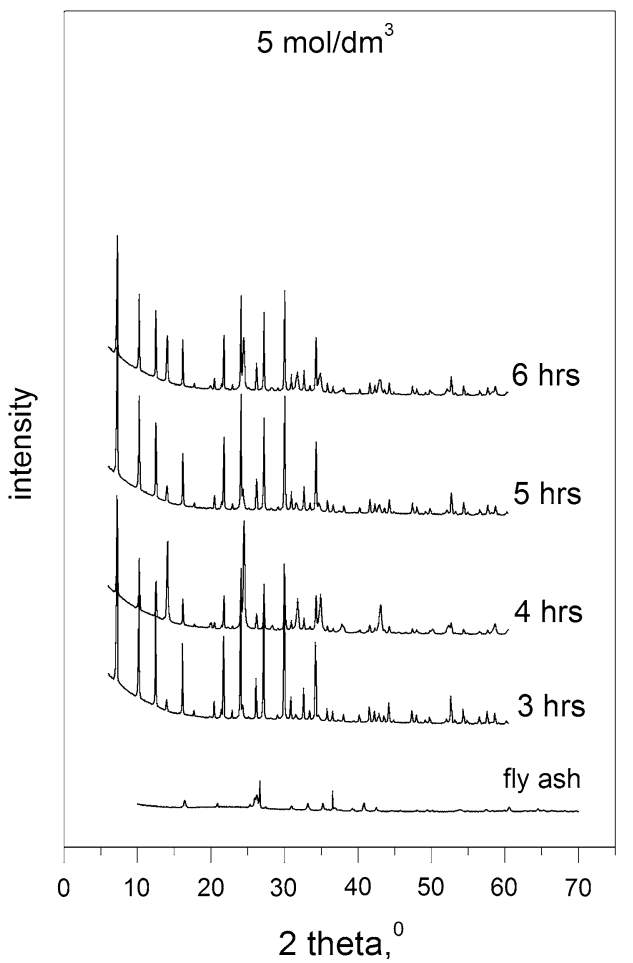

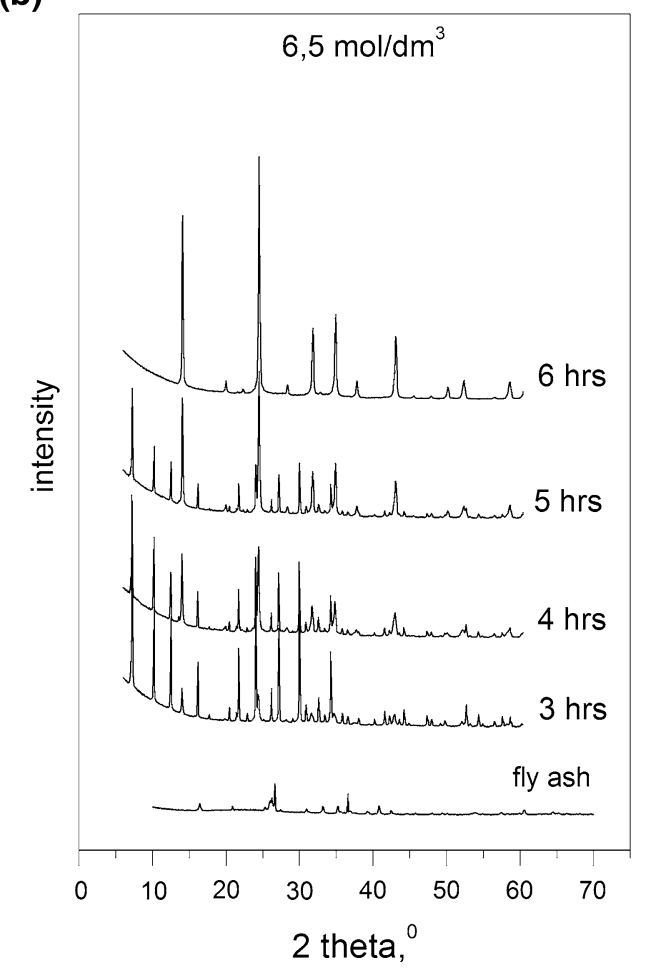

$\mathrm{NaOH}$ solution (regardless the crystallization time) and in the case of using 3.3 and $5 \mathrm{~mol} / \mathrm{dm}^{3} \mathrm{NaOH}$ solutions (but only with $3 \mathrm{~h}$ ' crystallization time, and that were only traces). In other cases, a high degree of purity Na-A zeolite was obtained.
A monomineral Na-A zeolite was obtained with using a $1.5 \mathrm{~mol} / \mathrm{dm}^{3} \mathrm{NaOH}$ solution for obtaining the $\mathrm{Si}$ and $\mathrm{Al}$ filtrate, regardless the crystallization time, which indicates that this is the most favourable $\mathrm{NaOH}$ concentration for obtaining the filtrate suitable for recovering the high degree 


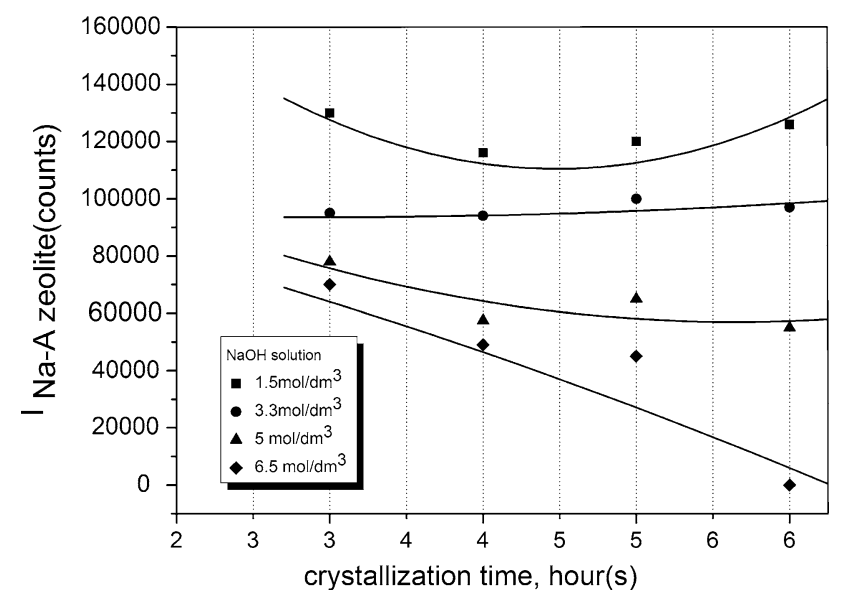

Fig. 5 Dependence of the (200) diffraction peak intensity on the crystallization time at different $\mathrm{NaOH}$ concentrations square experimental data; solid line simulated data

of purity Na-A zeolite from the fly ash by this method (the $\mathrm{Si} / \mathrm{Al}$ after adding $\mathrm{NaAlO}_{2}=2.0$ ).

The synthesis result was represented by the intensity $\mathrm{I}_{\mathrm{A}}$, of the most intense diffraction peak for fly ash-derived Na-A zeolite (Fig. 4) corresponding to the (200) Miller's indices $(2 \theta=7.178)$. Figure 5 represents the dependence of the (200) diffraction peak intensity, $\mathrm{I}_{\mathrm{A}}$, of the Na-A zeolite on the crystallization time at different $\mathrm{NaOH}$ concentrations used for obtaining the $\mathrm{Si}$ and $\mathrm{Al}$ extract from the fly ash. As follows from Fig. 5, with increasing crystallization time, the (200) diffraction peak intensity, $\mathrm{I}_{\mathrm{A}}$, of the Na-A zeolite slightly increases in the case, where the 1.5 and $3.3 \mathrm{~mol} / \mathrm{dm}^{3}$ materials was evaluated by calculating the thermogravimetric factor of conversion $\left(\mathrm{CF}_{\mathrm{TGA}}\right)$ of fly ash to the zeolite material, as proposed in the study.

\subsection{Thermogravimetric fly ash-to-zeolite conversion factor- $\mathrm{CF}_{\mathrm{TGA}}$}

Tests of the dehydration of fly ash zeolites carried out by the thermogravimetric method [20] have suggested a possibility of using this method for the evaluation of degree of conversion of fly ash into zeolite material alongside the CEC, XRD, BET and IR methods being currently proposed for this purpose. The present work proposes the calculation of the thermogravimetric fly ash-to-zeolite conversion factor, $\mathrm{CF}_{\mathrm{TGA}}$, based on the comparison of the mass loss of the commercial (pure) zeolite occurred during dehydration with that of the fly ash-derived zeolite. This mass loss is characteristic of a specific zeolite type, and the corresponding zeolite water content of the zeolite sample indicates their degree of crystallinity and zeolite phase content [21]. The basis for the determination of the conversion factor $\mathrm{CF}_{\mathrm{TGA}}$ are the $\mathrm{TG}$ curves of mass loss during heating of the commercial zeolite (standard) and the fly ash-derived zeolite. From the obtained values, the percentage fly ashto-zeolite conversion factor, $\mathrm{CF}_{\mathrm{TGA}}$, can be obtained, which is the ratio of the mass loss of the fly ash zeolite (due to its dehydration) to the mass loss (due to dehydration) of the commercial zeolite (standard) synthesized classically from chemically pure components, according for formula 1 .

$\mathrm{CF}_{\mathrm{TGA}}[\%]=\frac{\text { The mass loss of the fly ash zeolite (due to its dehydration) }}{\text { The mass loss of the commercial zeolite }- \text { standard (due to its dehydration })} \times 100$

$\mathrm{NaOH}$ solutions were used for fly ash activation, and decreases with increasing crystallization time, when 5 and $6.5 \mathrm{~mol} / \mathrm{dm}^{3} \mathrm{NaOH}$ solutions were used for fly ash activation. The highest (200) diffraction peak intensities, $\mathrm{I}_{\mathrm{A}}$, of the Na-A zeolite are observed in the case of using the $1.5 \mathrm{~mol} /$ $\mathrm{dm}^{3} \mathrm{NaOH}$ solution for activation. Thus, when $\mathrm{NaOH}$ solutions of higher concentrations are used, shorter crystallization times are definitely more advantageous, as the Na-A phase content of the sample decreases with increasing crystallization time. In the case of using lower concentrations of $\mathrm{NaOH}$ solution, the crystallization time plays a less important role, and a material of a substantial $\mathrm{Na}-\mathrm{A}$ phase content can be obtained already after $3 \mathrm{~h}$ of crystallization. The degree of fly ash conversion to Na-P1 and $\mathrm{Na}-\mathrm{A}$ zeolite
Figure 6 shows TG curves for Na-P1 zeolites obtained from fly ash by hydrothermal synthesis (using $2 \mathrm{~mol} / \mathrm{dm}^{3}$ $\mathrm{NaOH}$ solutions, $125^{\circ} \mathrm{C}$, and a synthesis duration of 8,12 and $24 \mathrm{~h}$ ), as well as for an Na-P1 zeolite produced from an $\mathrm{Si}$ fly ash extract by a two-stage method. Based on the values red out from the TG mass loss curves and using formula (1), $\mathrm{CF}_{\mathrm{TGA}}$ thermogravimetric conversion factors were calculated, which amounted to 55, 76.5 and $62 \%$, respectively, for the Na-P1 zeolites obtained after 8,12 and $24 \mathrm{~h}$ of crystallization, and $91 \%$ for the Na-P1 zeolite produced from the fly ash extract by the two-stage method. The obtained values show that in the case of the hydrothermal conversion of fly ash into the zeolite Na-P1 the most favourable synthesis duration was $12 \mathrm{~h}$ (using a 


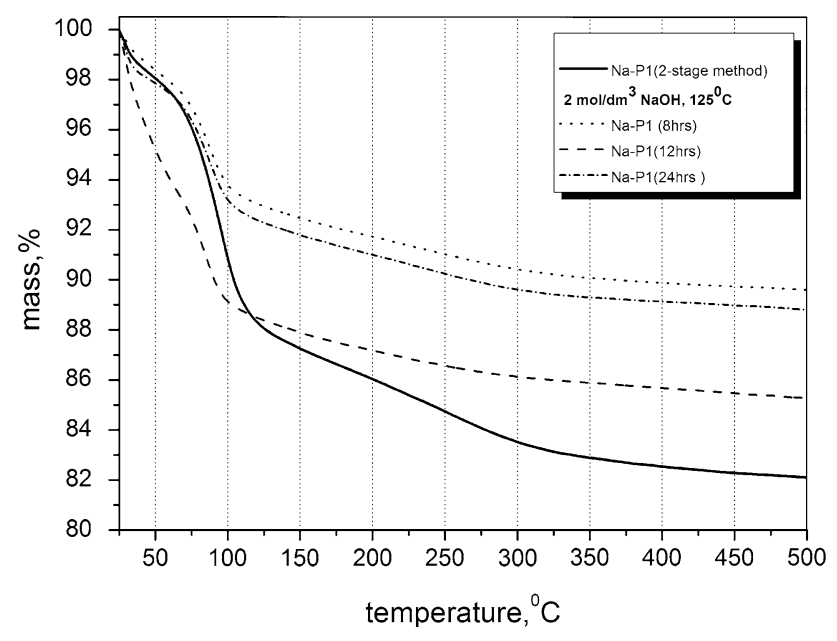

Fig. 6 Thermogravimetric (TG) curves of Na-P1 zeolite obtained from fly ash by hydrothermal activation (using a $2 \mathrm{~mol} / \mathrm{dm}^{3} \mathrm{NaOH}$ solution, $125{ }^{\circ} \mathrm{C}$, and a synthesis duration of 8,12 and $24 \mathrm{~h}$ ) and from an $\mathrm{Si}$ fly ash extract by a two-stage method, respectively (heating rate: $20{ }^{\circ} \mathrm{C} \min ^{-1}$; nitrogen flow: $50 \mathrm{~cm}^{3} \mathrm{~min}^{-1}$ )

$2 \mathrm{~mol} / \mathrm{dm}^{3} \mathrm{NaOH}$ solution, at $125^{\circ} \mathrm{C}$ ). The lower values of the fly ash-to-zeolite conversion factor achieved for the Na-P1 zeolites produced by the direct hydrothermal conversion method indicate that the zeolites obtained by this method contain considerable amounts of impurities left from the fly ash. Calculations of the $\mathrm{CF}_{\mathrm{TGA}}$ thermogravimetric conversion factor were also carried out for Na-A zeolite obtained by the direct hydrothermal activation method. Figure 7 represents TG curves for the commercial $\mathrm{Na}-\mathrm{A}$ zeolite (standard) and for Na-A zeolites obtained from fly ash as a result of hydrothermal activation based on the fly ash extract with the use of a $3.3 \mathrm{~mol} / \mathrm{dm}^{3} \mathrm{NaOH}$ solution and after crystallization for 3, 4, 5 and $6 \mathrm{~h}$. Based on the values red out from the TG curves (Fig. 7) and using formula (1), $\mathrm{CF}_{\mathrm{TGA}}$ thermogravimetric conversion factors were calculated, which amounted to $99,92,94.1$ and $90 \%$ for Na-A zeolites obtained after $3,4,5$ and $6 \mathrm{~h}$ of crystallization, respectively. The high degrees of fly ash conversion into the Na-A zeolite material confirm that zeolites of a high purity level can be produced by the fly ash extract synthesis method. TG curves-based conversion factors were also calculated for Na-A zeolites obtained using 1.5; 5 and $6.5 \mathrm{~mol} / \mathrm{dm}^{3} \mathrm{NaOH}$ solutions and 3, 4, 5 and $6 \mathrm{~h}$ ' crystallization. For the Na-A zeolites produced using the $1.5 \mathrm{~mol} / \mathrm{dm}^{3}$ solution, the $\mathrm{CF}_{\mathrm{TGA}}$ conversion factor ranged from 92 to $96.8 \%$; for the Na-A zeolites produced using the $5 \mathrm{~mol} / \mathrm{dm}^{3}$ solution, from 80 to $97.7 \%$; and for the NaA zeolites produced using the $6.5 \mathrm{~mol} / \mathrm{dm}^{3}$ solution, from 65 to $88.2 \%$. A summary of $\mathrm{CF}_{\mathrm{TGA}}$ thermogravimetric conversion factor values for Na-A zeolites produced by fly ash extract hydrothermal activation under different synthesis conditions, including time and $\mathrm{NaOH}$ concentration, is provided in Fig. 8. The obtained results indicate a lower

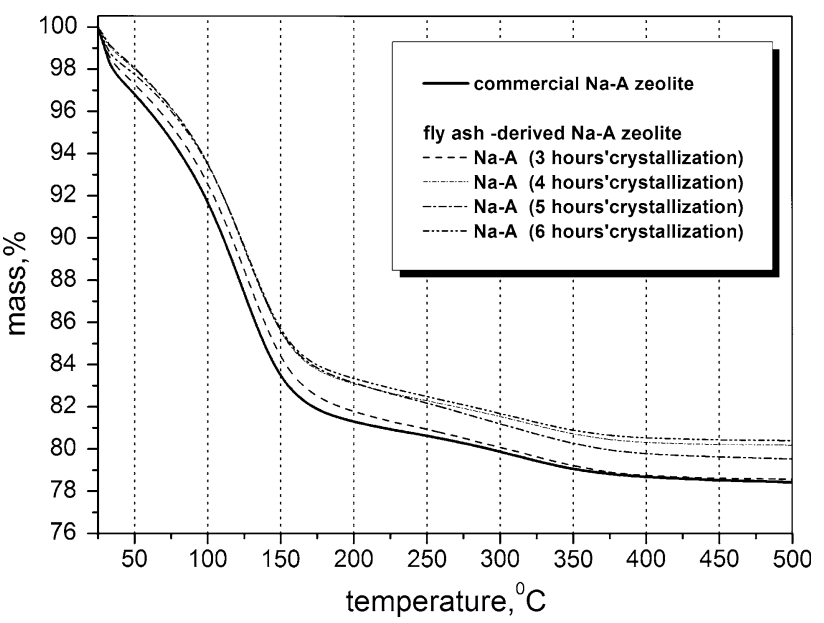

Fig. 7 Thermogravimetric (TG) curves of commercial Na-A zeolite and Na-A zeolites produced from fly ash as a result of hydrothermal reaction based on the fly ash extract using a $3.3 \mathrm{~mol} / \mathrm{dm}^{3} \mathrm{NaOH}$ solution and after 3, 4, 5 and 6 h' crystallization (heating rate: $20{ }^{\circ} \mathrm{C} \mathrm{m^{-1 }}{ }^{-1}$ nitrogen flow: $50 \mathrm{~cm}^{3} \mathrm{~min}^{-1}$ )

fly ash-to-zeolite conversion degree in the fly ash extract synthesis method in the case of using $\mathrm{NaOH}$ solutions of a higher concentration and longer crystallization times. The obtained results for the thermogravimetric conversion factor $\left(\mathrm{CF}_{\mathrm{TGA}}\right)$ for the zeolites $\mathrm{Na}-\mathrm{P} 1$ and $\mathrm{Na}-\mathrm{A}$ were compared with the values of the $\mathrm{X}$-ray conversion factor $\left(\mathrm{CF}_{\mathrm{XRD}}\right)$ and the $\mathrm{CEC}$ conversion factor $\left(\mathrm{CF}_{\mathrm{CEC}}\right)$ of the fly ash-derived zeolite materials. The fly ash-to-zeolite conversion degree results obtained for Na-P1 zeolites and selected Na-A zeolite materials are given in Table 2. As can be seen from the data in Table 2, the results obtained by different methods differ, which indicates how important it is to specify the procedure and methodology of calculating the fly ash-to-zeolite conversion degree when reporting the results of syntheses.

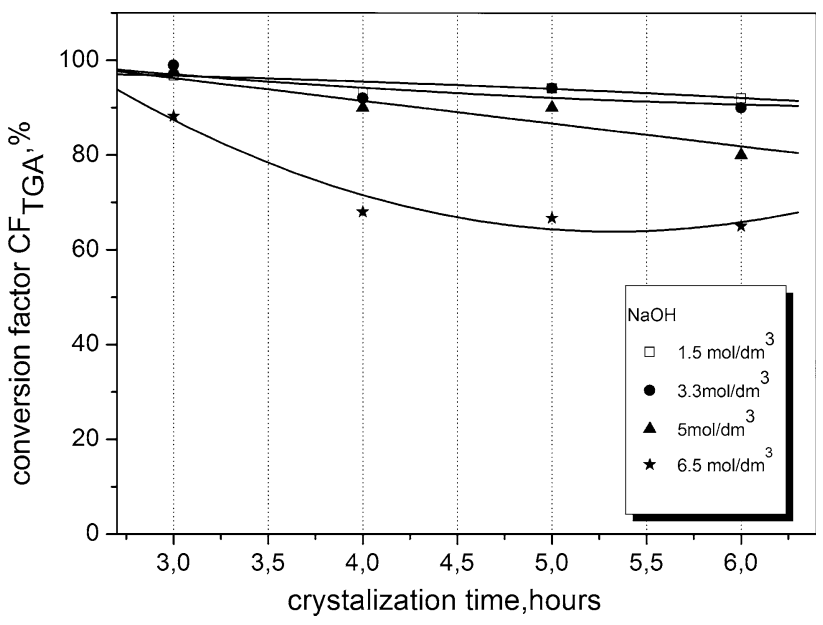

Fig. $8 \mathrm{CF}_{\mathrm{TGA}}$ thermogravimetric conversion factors for fly ashderived $\mathrm{Na}-\mathrm{A}$ zeolite obtained from the fly ash extract by the hydrothermal activation method 
Table 2 The fly ash-to-zeolite conversion factor $(\%)$ as determined by the CEC, XRD and TGA methods for selected fly ash-derived zeolite

\begin{tabular}{llll}
\hline \multicolumn{2}{l}{ Conversion factor $(\mathrm{CF})$} & \\
\cline { 2 - 4 } & $\mathrm{CF}_{\mathrm{CEC}}(\%)$ & $\mathrm{CF}_{\mathrm{XRD}}(\%)$ & $\mathrm{CF}_{\mathrm{TGA}}(\%)$ \\
\hline Commercial zeolite & & & 100 \\
Na-A & 100 & 100 & 100 \\
Na-P1 & 100 & 100 & \\
Fly ash-derived zeolite & & & 91.0 \\
Na-P1 & 92.0 & 94.0 & 55.0 \\
Na-P1 $\left(2 \mathrm{~mol} / \mathrm{dm}^{3}, 8 \mathrm{~h}\right)$ & 63.7 & 52.0 & 76.5 \\
Na-P1 $\left(2 \mathrm{~mol} / \mathrm{dm}^{3}, 12 \mathrm{~h}\right)$ & 77.4 & 72.0 & 62.0 \\
Na-P1 $\left(2 \mathrm{~mol} / \mathrm{dm}^{3}, 24 \mathrm{~h}\right)$ & 74.1 & 52.0 & 99.0 \\
Na-A $\left(3.3 \mathrm{~mol} / \mathrm{dm}^{3}, 3 \mathrm{~h}\right)$ & 98.0 & 92.7 & 92.0 \\
Na-A $\left(3.3 \mathrm{~mol} / \mathrm{dm}^{3}, 4 \mathrm{~h}\right)$ & 98.5 & 92.0 & 94.1 \\
Na-A $\left(3.3 \mathrm{~mol} / \mathrm{dm}^{3}, 5 \mathrm{~h}\right)$ & 94.9 & 94.0 & 90.0 \\
Na-A $\left(3.3 \mathrm{~mol} / \mathrm{dm}^{3}, 6 \mathrm{~h}\right)$ & 93.5 & 93.5 &
\end{tabular}

\section{Conclusions}

The use of the TGA method for the indirect determination of the fly ash-to-zeolite conversion factor would be preferable owing to its "speed" compared to other methods proposed for this purpose, as well as the capability to use a consistent procedure. Because of its short $\mathrm{CF}_{\mathrm{TGA}}$ determination procedure, the thermogravimetric method can be used for the control and determination of the quality of fly ash zeolite products in an industrial plant.

Acknowledgments Scientific work was supported by the National Science Centre (Poland), as Project Investigations of $\mathrm{CO}_{2}$ adsorption/ desorption on amine-impregnated fly ash-derived zeolite (7506/B/ T02/2011/40). The author is grateful for this support.

Open Access This article is distributed under the terms of the Creative Commons Attribution License which permits any use, distribution, and reproduction in any medium, provided the original author(s) and the source are credited.

\section{References}

1. J.G.S. van Jaarsveld, J.S.J. van Deventer, G.C. Lukey, The characterisation of source materials in fly ash-based geopolymers. Mater. Lett. 57, 1272-1280 (2003)

2. D. Paniasa, I.P. Giannopoulou, T. Perraki, Effect of synthesis parameters on the mechanical properties of fly ash-based geopolymers. Colloids Surf. A Physicochem. Eng. Asp. 301, 246-254 (2007)

3. J.C. Swanepoel, C.A. Strydom, Utilisation of fly ash in a geopolymeric material. Appl. Geochem. 17, 1143-1148 (2002)

4. N.F. Gao, S. Kume, K. Watari, Zeolite-carbon composites prepared from industrial wastes: (I) effects of processing parameters. Mater. Sci. Eng. A 399, 216-221 (2005)

5. N.F. Gao, S. Kume, K. Watari, Zeolite-carbon composites prepared from industrial wastes: (II) evaluation of the adaptability as environmental materials. Mater. Sci. Eng. A 399, 216-221 (2005)

6. T.T. Suchecki, Zeolity z popiołów lotnych. Otrzymywanie i aplikacje w inżynierii środowiska. Zakład Narodowy im. Ossolińskich -Wydawnictwo Wrocław, (2005)

7. H.-L. Chang, W.H. Shih, A general method for the conversion of fly ash into zeolites as ion exchangers for cesium. Ind. Eng. Chem. Res. 37, 71-78 (1998)

8. A. Singer, V. Berkgaut, Cation exchange properties of hydrothermally treated coal fly ash. Environ. Sci. Technol. 29, 1748-1753 (1995)

9. W.-H. Shih, H.-L. Chang, Conversion of fly ash into zeolites for ion-exchange applications. Mater. Lett. 28, 263-268 (1996)

10. N.R.C.F. Machado, D.M.M. Miotto, Synthesis of Na-A and-X zeolites from oil shale ash. Fuel 84, 2289-2294 (2005)

11. X. Querol, J.C. Umana, F. Plana, A. Alastuey, A. Lopez-Soler, A. Medinaceli, A. Valero, M.J. Domingo, E. Garcia-Rojo, Synthesis of zeolites from fly ash at pilot plant scale. Examples of potential applications. Fuel 80, 857-865 (2001)

12. X. Querol, N. Moreno, A. Alastuey, R. Juan, J.M. Andres, A. Lopez-Soler, C. Ayora, A. Medinaceli, A. Valero, Synthesis of high ion exchange zeolites from fly ash. Geol. Acta 5, 49-57 (2007)

13. O. Font, N. Moreno, S. Diez, X. Querol, A. Lopez-Soler, P. Coca, F.G. Pena, Differential behaviour of combustion and gasification fly ash from Puertollano Power Plants (Spain) for the synthesis of zeolites and silica extraction. J. Hazard. Mater. 166(1), 94-102 (2009)

14. R. Moriyama, S. Takeda, M. Onozaki, Y. Katayama, K. Shiota, T. Fukuda, H. Sugihara, Y. Tani, Large-scale synthesis of artificial zeolite from coal fly ash with a small charge of alkaline solution. Fuel 84, 1455-1461 (2005)

15. S.S. Rayalu, J.S. Udhoji, S.U. Meshram, R.R. Naidu, S. Devotta, Estimation of crystallinity in fly ash-based zeolite-A using XRD and IR spectroscopy. Curr. Sci. 89, 2147-2151 (2005)

16. M. Gross-Lorgouillox, M. Soulard, P. Caullet, J. Patarin, E. Moleiro, I. Saude, Conversion of coal fly ashes into faujasite under soft temperature and pressure conditions: influence of additional silica. Microporous Mesoporous Mater. 127, 41-49 (2010)

17. M. Gross, M. Soulard, P. Caullet, J. Patarin, I. Saude, Synthesis of faujasite from coal fly ashes under smooth temperature and pressure conditions: a cost saving process. Microporous Mesoporous Mater. 104, 67-76 (2007) 
18. G.G. Hollman, G.M. Steenbruggen, M. Janssen-Jurkovicova, A two-step process for the synthesis of zeolites from coal fly ash. Fuel 78, 1225-1230 (1999)

19. Y. Fan, F.S. Zhang, J. Zhu, Z. Liu, Effective utilization of waste ash from MSW and coal co-combustion power plant-Zeolite synthesis. J. Hazard. Mater. 153, 382-388 (2008)
20. I. Majchrzak-Kucęba, W. Nowak, Thermal analysis of fly ashbased zeolites. J. Therm. Anal. Calorim. 77, 125-131 (2004)

21. D.W. Breck, Zeolite molecular sieves-structure, chemistry, and use (Wiley, New York, 1974) 